\title{
Screening of Potential Anti-Thrombotic Ingredients from Salvia miltiorrhiza in Zebrafish and by Molecular Docking
}

\author{
Huilan Tang ${ }^{1,+}$, Ningyi Qin ${ }^{2,+}$, Chang Rao ${ }^{1}$, Jiahui Zhu ${ }^{1}$, Haiqiang Wang ${ }^{1}$ and Guang Hu ${ }^{1,3, * \mathbb{D}}$ \\ 1 School of Pharmacy and Bioengineering, Chongqing University of Technology, Chongqing 400054, China; \\ BellaT@2019.cqut.edu.cn (H.T.); raochang2021@hotmail.com (C.R.); zhujh@2020.cqut.edu.cn (J.Z.); \\ whq723366140@hotmail.com (H.W.) \\ 2 Chongqing Pharmaceutical Group Huamosheng Pharmaceutical Science \& Technology Co., Ltd., \\ Chongqing 400050, China; vivianqny@163.com \\ 3 Chongqing Key Laboratory of Medicinal Chemistry \& Molecular Pharmacology, \\ Chongqing University of Technology, Chongqing 400054, China \\ * Correspondence: foxhu@cqut.edu.cn; Tel.: +86-150-2308-8936 \\ + Two authors contributed equally to the paper.
}

check for updates

Citation: Tang, H.; Qin, N.; Rao, C.; Zhu, J.; Wang, H.; Hu, G. Screening of Potential Anti-Thrombotic

Ingredients from Salvia miltiorrhiza in Zebrafish and by Molecular Docking. Molecules 2021, 26, 6807. https:// doi.org/10.3390/molecules26226807

Academic Editors: Ana

Estévez-Braun, Fengqing Yang,

Jianbo Wan and Liya Ge

Received: 2 October 2021

Accepted: 5 November 2021

Published: 11 November 2021

Publisher's Note: MDPI stays neutral with regard to jurisdictional claims in published maps and institutional affiliations.

Copyright: (c) 2021 by the authors. Licensee MDPI, Basel, Switzerland. This article is an open access article distributed under the terms and conditions of the Creative Commons Attribution (CC BY) license (https:/ / creativecommons.org/licenses/by/ $4.0 /)$.

\begin{abstract}
Background: Danshen (DS), the dry root of Salvia miltiorrhiza Bge., has been used in traditional Chinese medicine (TCM) for many years to promote blood circulation and to inhibit thrombosis. However, the active ingredients responsible for the anti-thrombotic effect and the underlying mechanisms are yet to be fully elucidated. Methods: Molecular docking was used to predict the active ingredients in DS and their potential targets by calculating the scores of docking between DS ingredients and thrombosis-related proteins. Then, a chemical-induced zebrafish thrombosis model was applied to confirm their anti-thrombotic effects. Result: The molecular docking results indicated that compared to the control ligand, higher docking scores were observed for several compounds in DS, among which salvianolic acid B (SAB), lithospermic acid (LA), rosmarinic acid (MA), and luteolin-7-O- $\beta$-D-glucoside (LG) could attenuate zebrafish caudal vein thrombosis and recover the decrease in heart red blood cells (RBCs) in a dose-dependent manner. Conclusions: Our study showed that it is possible to screen the potential active components in natural products by combining the molecular docking method and zebrafish in vivo model.
\end{abstract}

Keywords: zebrafish; molecular docking; salvianolic acid B; rosmarinic acid; lithospermic acid; luteolin-7-O- $\beta$-D-glucoside; anti-thrombotic effects

\section{Introduction}

Thrombosis is characterized by intravascular thrombus formation and vessel occlusion, which may result in myocardial infarction, ischemia, and stroke, and it can be especially dangerous if it blocks blood flow to organs or tissues [1]. Thrombus formation in blood vessels is usually associated with systemic disorders such as hypercoagulability [2]. As the leading cause of death worldwide $[3,4]$, thrombosis, which plays an important role in cardiovascular disease, seriously threatens human health and life $[5,6]$. Therefore, new drug development in thrombosis treatment is in great demand.

Traditional Chinese medicine (TCM) has been widely applied in clinical therapy in China and other countries [7-9] for a long time. According to the TCM theory, thrombosis belongs to the syndrome of blood stasis. Many herbal formulae and extracts are used to treat blood stasis syndrome (BSS) via promoting blood circulation, inhibiting platelet aggregation, and promoting the hemostasis release reaction $[10,11]$. Danshen (DS), the dry root of Salvia miltiorrhiza Bge. which can also be used in food and healthy supplement $[12,13]$, has attracted increasing attention as a treatment option for cardiovascular and cerebrovascular diseases $[13,14]$. DS, which contains more than 200 chemical constituents including salvianolic acid B (SAB), danshensu (DSS), lithospermic acid (LA), rosmarinic 
acid (MA) [15], and luteolin-7-O- $\beta$-D-glucoside (LG), is a commonly used medicine for "invigorating" the blood and reducing blood clotting [16]. For example, many studies have shown that DS can inhibit platelet aggregation and adhesion, improve blood microcirculation, and reduce thrombus formation [17]. Therefore, DS has been extensively used to cure cardiovascular and cerebrovascular diseases, inflammatory diseases, and neurodegeneration diseases [15]. Furthermore, it has been demonstrated that the extract of the herb has effects against hemostasis as well as eliminating blood stasis. However, the active ingredients responsible for the anti-thrombotic effect in DS and their target proteins are yet to be fully elucidated.

Virtual screening based on molecular docking is a computational technique used in drug discovery research. It can deal with the quick search of large molecular libraries to identify the structures that are most likely to bind the drug target, which is typically a protein receptor or enzyme [18]. In recent years, molecular docking, which plays an important role in drug screening and design [19], is one of the most frequently and effectively used methods to predict the optimal binding mode (binding sites and binding poses) and affinity between a small molecule drug candidate (ligand) and a target protein (receptor) [20-22]. Several compounds including lithospermate B, salvianolic acid C, lithospermate acid B, magnesium lithospermate B, danshensuan B, salvianolic Acid B, monomethyl lithospermate, and oleoyl neocryptotanshinone in DS have been identified as ingredients with potential anti-thrombotic activity with this approach [18].

Zebrafish (Danio rerio) has been used in the past few years to identify novel factors of hemostasis and thrombosis, and to analyze their functions in greater detail [23-26]. Compared to the conventional mammal in vivo models, which are usually laborious, costly, and time consuming [27], the zebrafish model organism has a large number of advantages including high fecundity, small size, rapid development, and rapid generation time [28]. In fact, zebrafish is considered to be especially appropriate for the research of angiocardiopathy than other models because the endogenous blood circulation can be dynamically observed without invasive methods [16], and there is remarkable similarity in the cardiovascular system between zebrafish and humans [29,30]. Furthermore, with the capability of percutaneous oxygen absorption, zebrafish embryos could survive for a long time without functional blood circulation, during which the investigation of antithrombotic agents could be done [31].

In the present study, virtual screenings based on molecular docking between components in DS and thrombosis-related protein targets were performed. Potential active ingredients and possible protein targets were predicted according to the docking scores. Then, candidates of active compounds in DS with potential anti-thrombotic effect were treated to chemical-induced thrombosis zebrafish to validate their ability of promoting blood circulation and eliminating blood stasis.

\section{Results and Discussion}

\subsection{Analysis of Molecular Docking}

The structure information of 202 compounds in DS were obtained from the Traditional Chinese Medicine Systems Pharmacology Database and Analysis Platform (TCMSP) (https: / / old.tcmsp-e.com/tcmsp.php, accessed on 4 November 2021). The relevant target proteins of thrombosis were collected in the Therapeutic Target Database (TTD) (http:/ / db.idrblab. net/ttd/, accessed on 4 November 2021), and 31 target proteins were obtained, including a successful target, clinical trial target, discontinued target, and literature-reported target. Then, the corresponding X-ray crystallographic structures with higher resolution were searched through the UniProt (https:/ / www.uniprot.org, accessed on 4 November 2021) database, and 25 crystal structures were selected from the Protein Data Bank (PDB) (http: / / www.rcsb.org/, accessed on 4 November 2021) database for subsequent experiments. Finally, 202 active ingredients in DS were docked with 25 target proteins respectively, and the results are shown in Tables 1 and 2. On one hand, a thrombosis-related target protein could combine well with multiple ligands, e.g., antithrombin-III (ATIII, PDB ID:1R1L) 
could bind to 160 ingredients in DS; on the other hand, one compound in DS would bind to 10-15 thrombosis-related targets. According to the docking result, many small molecules in DS could bind to the same proteins including 1R1L, 5AFY, 4C2A, 6TS4, 3QX3, 3T3M, $2 \mathrm{JKH}$, and 5AFN. Among all the compounds that could combine with multiple thrombosisrelated targets in Table 2, SAB, MA, LA, and LG (structures shown in Figure 1), which were characteristic compounds of DS and can be commercially obtained with high purity, were selected for further in vivo pharmacological tests. The docking scores of SAB, MA, LA, and LG are shown in Table 3.

Table 1. The number of compounds in DS that could bind to thrombosis-related enzymes.

\begin{tabular}{|c|c|c|c|}
\hline Number & Target Name & PDB ID & Number of Compounds \\
\hline 1 & Antithrombin III (ATIII) & 1R1L & 160 \\
\hline 2 & Coagulation factor IIa (F2) & $5 \mathrm{AFY}$ & 143 \\
\hline 3 & von Willebrand factor (VWF) & $4 \mathrm{C} 2 \mathrm{~A}$ & 143 \\
\hline 4 & Coagulation factor XI (F11) & 6TS4 & 110 \\
\hline 5 & Plasminogen activator inhibitor (PAI) & 1JRR & 100 \\
\hline 6 & Neuronal acetylcholine receptor beta-2 (CHRNB2) & $6 \mathrm{NCJ}$ & 88 \\
\hline 7 & DNA topoisomerase II (TOP2) & $3 Q \times 3$ & 73 \\
\hline 8 & Neuronal acetylcholine receptor alpha-2/alpha-3 (CHRNA2/A3) & $4 Z K 4$ & 50 \\
\hline 9 & Glycoprotein IIb/IIIa receptor (GPIIb/IIIa) & 3Т3M & 43 \\
\hline 10 & Coagulation factor Xa (F10) & 2JKH & 40 \\
\hline 11 & P-selectin (SELP) & 1G1S & 38 \\
\hline 12 & Neuronal acetylcholine receptor alpha-2/alpha-3 (CHRNA2/A3) & $5 \mathrm{FJV}$ & 36 \\
\hline 13 & Neuronal acetylcholine receptor alpha-7 (CHRNA7) & $5 \mathrm{AFN}$ & 36 \\
\hline 14 & Tyrosine-protein kinase SYK (SYK) & $4 \mathrm{YJR}$ & 19 \\
\hline 15 & DNA topoisomerase II (TOP2) & $1 \mathrm{ZXN}$ & 16 \\
\hline 16 & P2Y purinoceptor 1 (P2RY1) & $4 \mathrm{XNV}$ & 5 \\
\hline 17 & Plasminogen activator inhibitor (PAI) & $2 \mathrm{HI} 9$ & 4 \\
\hline 18 & Coagulation factor IX (F9) & 5JB9 & 4 \\
\hline 19 & Carboxypeptidase B2 (CPB2) & $4 \mathrm{P} 10$ & 3 \\
\hline 20 & Platelet glycoprotein Ib alpha (CD42b) & $4 \mathrm{CH} 2$ & 3 \\
\hline 21 & Arachidonate 5-lipoxygenase (5-LOX) & $3 V 99$ & 2 \\
\hline 22 & Plasminogen activator inhibitor (PAI) & $4 G 8 R$ & 2 \\
\hline 23 & Proteinase activated receptor 1 (F2R) & 3VW7 & 1 \\
\hline 24 & P2Y purinoceptor 12 (P2RY12) & $4 \mathrm{PXZ}$ & 0 \\
\hline 25 & HMG-CoA reductase (HMGCR) & $2 \mathrm{R} 4 \mathrm{~F}$ & 0 \\
\hline
\end{tabular}

Table 2. Compounds in DS that could combine with more than nine thrombosis-related binding targets.

\begin{tabular}{cccc}
\hline Number & Mol ID & Molecule Name & Number of Targets \\
\hline 1 & MOL000069 & palmitic acid & 15 \\
2 & MOL000131 & EIC (linoleic acid) & 15 \\
3 & MOL000675 & oleic acid & 15 \\
4 & MOL002229 & HEPTACOSANE & 15 \\
5 & MOL007060 & lithospermic acid B & 15 \\
6 & MOL007116 & potassium salvianolate d & 15 \\
7 & MOL007129 & salvianolic acid e & 15 \\
8 & MOL007139 & stearic acid & 15 \\
9 & MOL000860 & 14 \\
\hline
\end{tabular}


Table 2. Cont.

\begin{tabular}{|c|c|c|c|}
\hline Number & Mol ID & Molecule Name & Number of Targets \\
\hline 10 & MOL004784 & stenol & 14 \\
\hline 11 & MOL007113 & lithospermic acid & 14 \\
\hline 12 & MOL007136 & salvianolic acid a & 14 \\
\hline 13 & MOL001219 & satol & 13 \\
\hline 14 & MOL004502 & monomethyl lithospermate & 13 \\
\hline 15 & MOL007083 & Z-8-hexadecen-1-ol acetate & 13 \\
\hline 16 & MOL007132 & $\begin{array}{c}\text { (2R)-3-(3,4-dihydroxyphenyl)-2-[(Z)-3-(3,4- } \\
\text { dihydroxyphenyl)acryloyl]oxy-propionic } \\
\text { acid }\end{array}$ & 13 \\
\hline 17 & MOL000865 & hexadecane & 12 \\
\hline 18 & MOL000869 & henicosane & 12 \\
\hline 19 & MOL001394 & oktadekan & 12 \\
\hline 20 & MOL002376 & pentacosane & 12 \\
\hline 21 & MOL007039 & henicosyl formate & 12 \\
\hline 22 & MOL007055 & 9-methyl lithospermate $b$ & 12 \\
\hline 23 & MOL007103 & dimetbyl lithosper-mate $b$ & 12 \\
\hline 24 & MOL007104 & dimethyllithospermate & 12 \\
\hline 25 & MOL007106 & ethyl lithospermate & 12 \\
\hline 26 & MOL007138 & salvianolic acid d & 12 \\
\hline 27 & MOL000128 & nerylacetate & 11 \\
\hline 28 & MOL002771 & VIV & 11 \\
\hline 29 & MOL007074 & salvianolic acid b & 11 \\
\hline 30 & MOL007135 & salvianic acid c & 11 \\
\hline 31 & MOL007137 & salvianolic acid c & 11 \\
\hline 32 & MOL007142 & salvianolic acid j & 11 \\
\hline 33 & MOL000009 & luteolin-7-o-glucoside & 10 \\
\hline 34 & MOL000054 & L- & 10 \\
\hline 35 & MOL000055 & L-lysin & 10 \\
\hline 36 & MOL000932 & alpha-farnesene & 10 \\
\hline 37 & MOL007044 & 3,7-dimethylocta-2,6-dien-1-yl formate & 10 \\
\hline
\end{tabular}

Table 3. Docking scores of SAB, RA, LA, and LG.

\begin{tabular}{ccccccccc}
\hline Molecular & 1R1L & 5AFY & 4C2A & 6TS4 & 3QX3 & 3T3M & 2JKH & 5AFN \\
\hline Original ligand & 2.18 & 3.61 & 3.93 & 3.88 & 3.31 & 6.36 & 6.22 & 6.71 \\
SAB & 4.12 & $\mathbf{1 2 . 5 8}$ & $\mathbf{8 . 9 1}$ & $\mathbf{9 . 7 5}$ & 4.50 & 7.38 & 6.60 & 7.12 \\
MA & $\mathbf{6 . 6 0}$ & 7.10 & 6.04 & 7.21 & $\mathbf{5 . 0 1}$ & 7.64 & 7.11 & 7.43 \\
LA & 2.78 & 9.14 & 8.40 & 7.57 & 4.19 & $\mathbf{9 . 7 0}$ & $\mathbf{8 . 1 4}$ & $\mathbf{7 . 4 9}$ \\
LG & 3.85 & 6.65 & 5.96 & 8.08 & 3.32 & 7.50 & 8.09 & 6.71 \\
\hline
\end{tabular}


<smiles>O=C(/C=C/c1ccc(O)c2c1[C@@H](C(=O)O[C@H](Cc1ccc(O)c(O)c1)C(=O)O)[C@H](c1ccc(O)c(O)c1)O2)O[C@@H](Cc1ccc(O)c(O)c1)C(=O)O</smiles><smiles>O=C(/C=C/c1ccc(O)c2c1[C@H](C(=O)O)[C@H](c1ccc(O)c(O)c1)O2)O[C@@H](Cc1ccc(O)c(O)c1)C(=O)O</smiles>

B<smiles>O=C(/C=C\c1ccc(O)c(O)c1)O[C@@H](Cc1ccc(O)c(O)c1)C(=O)O</smiles>

Figure 1. The structure of salvianolic acid $B(S A B)$, rosmarinic acid (MA), lithospermic acid (LA), and luteolin-7-O- $\beta$-D-glucoside (LG). (A-D) indicated as SAB, MA, LA, and LG, respectively.

To further explore the binding mode between the receptor and ligands, SAB, MA, LA, and LG were selected as active compounds for the molecular docking study. The interaction diagrams of the best-docked conformations are shown in Figure 2. The hydrogen bonds and amino acid residues of the interaction between coagulation factor XI (F11) (PDB ID: 6TS4) and the compounds are presented in Table 4. Hydrogen bonds play an important role in the binding of ligands to F11 that exist between SAB and TYR59A, ARG37D, GLY193, ALA195, GLY216, ALA97, GLY218, CYS219, CYS40, LEU39; MA and LEU39, CYS40, ASP189, CYS219, LYS192; LA and CYS58, ARG37D, ALA195, GLY193, ASP194, ASP189, GLY218, CYS219; as well as LG and ASP189, HIS57, GLU98, GLY193, ALA195, ASP194, TRP215, SER214, VAL227. Particularly, ALA195, GLY193, GLY216, CYS219, ASP189, and LYS192 are the most frequent amino acid residues, which may be the important residues for the interactions between ligands and F11. Moreover, the compounds containing hydroxyl and carbonyl, especially phenolic hydroxyl groups, are vital for hydrogen bond formation with F11. These results indicated that these compounds may be the potential active ingredients in DS with an anti-thrombotic effect. 
A

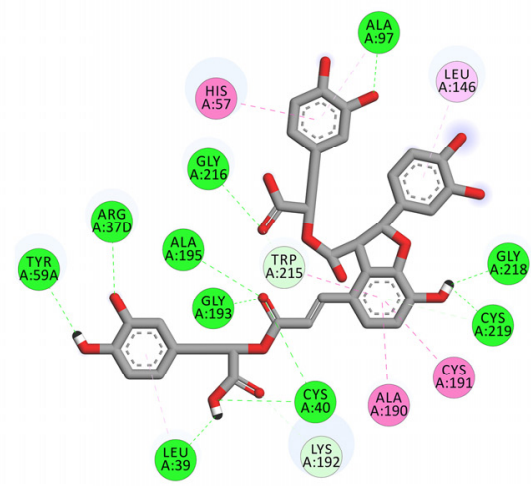

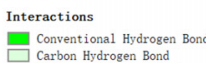
Canbont Hydrogen Bond
Pi-Donor Hydrogen Bond

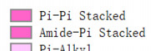

C $\begin{gathered}A R G \\ A: 370\end{gathered}$

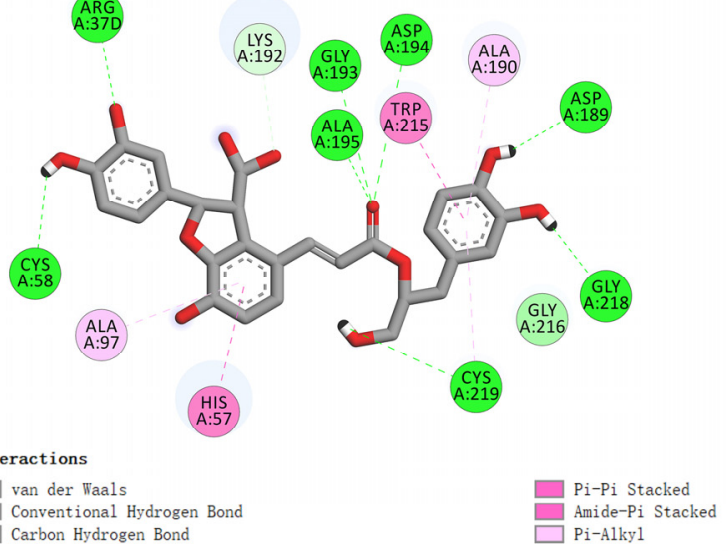

B

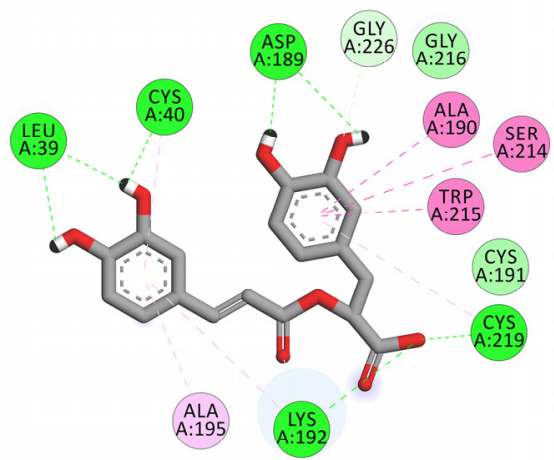

Interactions

$\square$ van der Waals

Conventional Hydrogen Bond

Carbon Hydrogen Bond
D

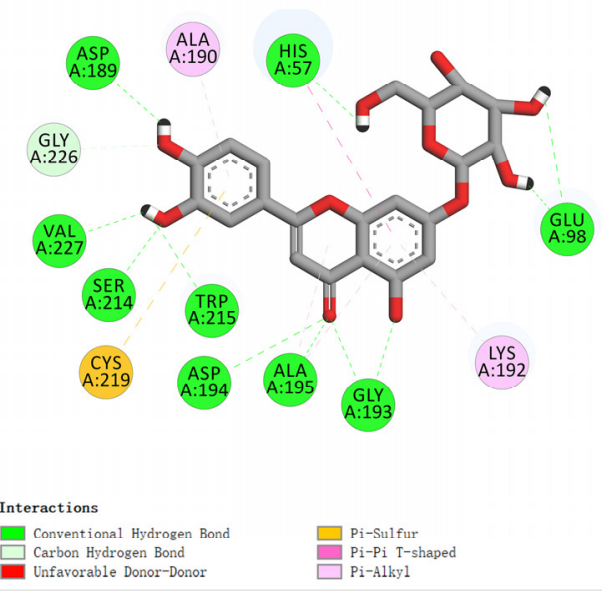

Figure 2. Docking results of the compounds SAB (A), MA (B), LA(C), and LG (D) with the coagulation factor XI (F11) (PDB ID: 6TS4).

Table 4. Docking results of investigated small-molecule compounds with F11.

\begin{tabular}{ccc}
\hline Compounds & Hydrogen Bonds & Other Amino Acid Residues \\
\hline \multirow{2}{*}{ SAB } & TYR59A, ARG37D, GLY193, ALA195, GLY216, ALA97, & TRP215, LYS192, HIS57, LEU146, CYS191, ALA190 \\
MA & GLY218, CYS219, CYS40, LEU39 & ALA195, GLY226, GLY216, ALA190, SER214, TRP215, \\
CYS191 \\
LA & CYS58, ARG37D, ALP189, CYS219, LYS192 & GLY218, CYS219 \\
LG & ASP189, HIS57, GLU98, GLY193, ALA195, ASP194, & ALA97, HIS57, LYS192, TRP215, ALA190, GLY216 \\
& TRP215, SER214, VAL227 & GLY226, CYS219, ALA190, LYS192 \\
\hline
\end{tabular}

\subsection{Assessment of the Anti-Thrombotic Effect of $S A B, M A, L A$, and $L G$}

Compared with the control group, the thrombus in the caudal vein of the $\mathrm{PHZ} / \mathrm{AH}$ treatment group was obviously increased, while the intensity of red blood cells (RBCs) in the heart decreased significantly, as shown in Figure 3(B1-B4). However, ASP, SAB, MA, LA, and LG could significantly reduce the chemical-induced thrombus in the caudal vein and recover the chemical-induced decrease in RBCs intensity in the heart. 


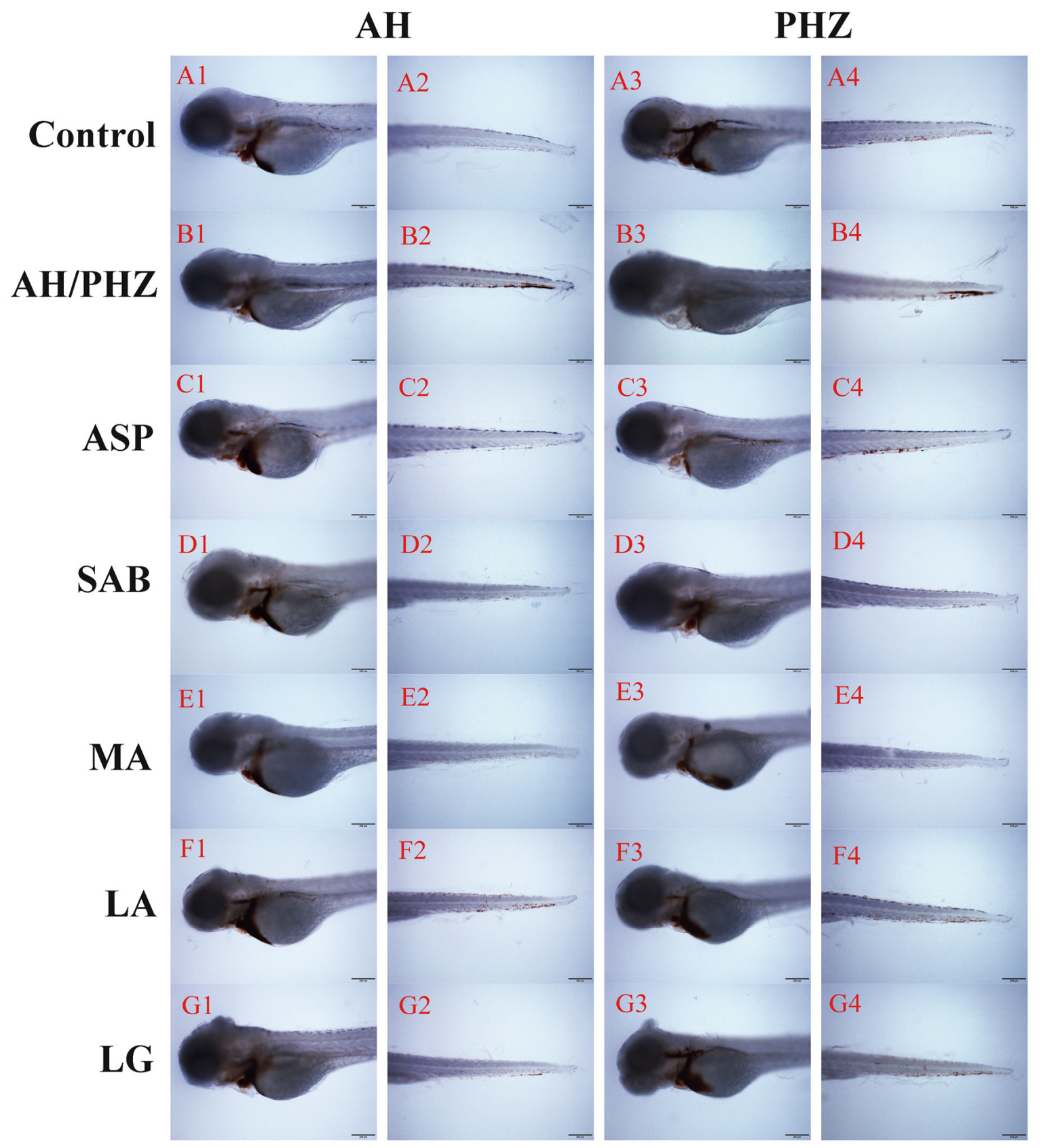

Figure 3. The RBC staining intensity of heart or caudal vein in zebrafish thrombus treated with different DS compounds. Rows (A-G) indicated the control, AH/PHZ, ASP, SAB, MA, LA, and LG group, respectively. Chemical inducers in columns 1 and 2 are $\mathrm{AH}$, while $\mathrm{PHZ}$ is used for columns 3 and 4.

In AH-induced thrombus treatment groups, statistically significant anti-thrombotic effects in pre-treatment zebrafish groups were observed at 25 and $50 \mu \mathrm{g} / \mathrm{mL}(p<0.001)$ for ASP; 12.5, 25, 50, 100, and $200 \mu \mathrm{g} / \mathrm{mL}(p<0.001)$ for SAB; $12.5 \mu \mathrm{g} / \mathrm{mL}(p<0.05), 25,50,100$, and $200 \mu \mathrm{g} / \mathrm{mL}(p<0.001)$ for MA; $25 \mu \mathrm{g} / \mathrm{mL}(p<0.01), 50,100$, and $200 \mu \mathrm{g} / \mathrm{mL}(p<0.001)$ for LA; $12.5 \mu \mathrm{g} / \mathrm{mL}(p<0.05), 25$ and $50 \mu \mathrm{g} / \mathrm{mL}(p<0.01), 100$ and $200 \mu \mathrm{g} / \mathrm{mL}(p<0.001)$ for LG. These results are shown in Figure 4 . The $\mathrm{IC}_{50}$ of ASP, SAB, MA, LA, and LG were calculated as $19.08,12.22,22.07,31.12$, and $62.75 \mu \mathrm{g} / \mathrm{mL}$, respectively (Table 5). Statistically significant anti-thrombotic effects in post-treatment zebrafish groups were observed at 25 and $50 \mu \mathrm{g} / \mathrm{mL}(p<0.01)$ for ASP; $25 \mu \mathrm{g} / \mathrm{mL}(p<0.05), 50,100$, and $200 \mu \mathrm{g} / \mathrm{mL}(p<0.01)$ for SAB; 25 and $50 \mu \mathrm{g} / \mathrm{mL}(p<0.01), 100$ and $200 \mu \mathrm{g} / \mathrm{mL}(p<0.001)$ for MA; $25 \mu \mathrm{g} / \mathrm{mL}$ $(p<0.05), 50,100$, and $200 \mu \mathrm{g} / \mathrm{mL}(p<0.01)$ for LA; 50, 100, and $200 \mu \mathrm{g} / \mathrm{mL}(p<0.01)$ for 
LG (Figure 4). The IC I0 $_{50}$ of ASP, SAB, MA, LA, and LG were calculated as 27.22, 27.23, 31.03, 50.62 , and $85.22 \mu \mathrm{g} / \mathrm{mL}$, respectively (Table 5).
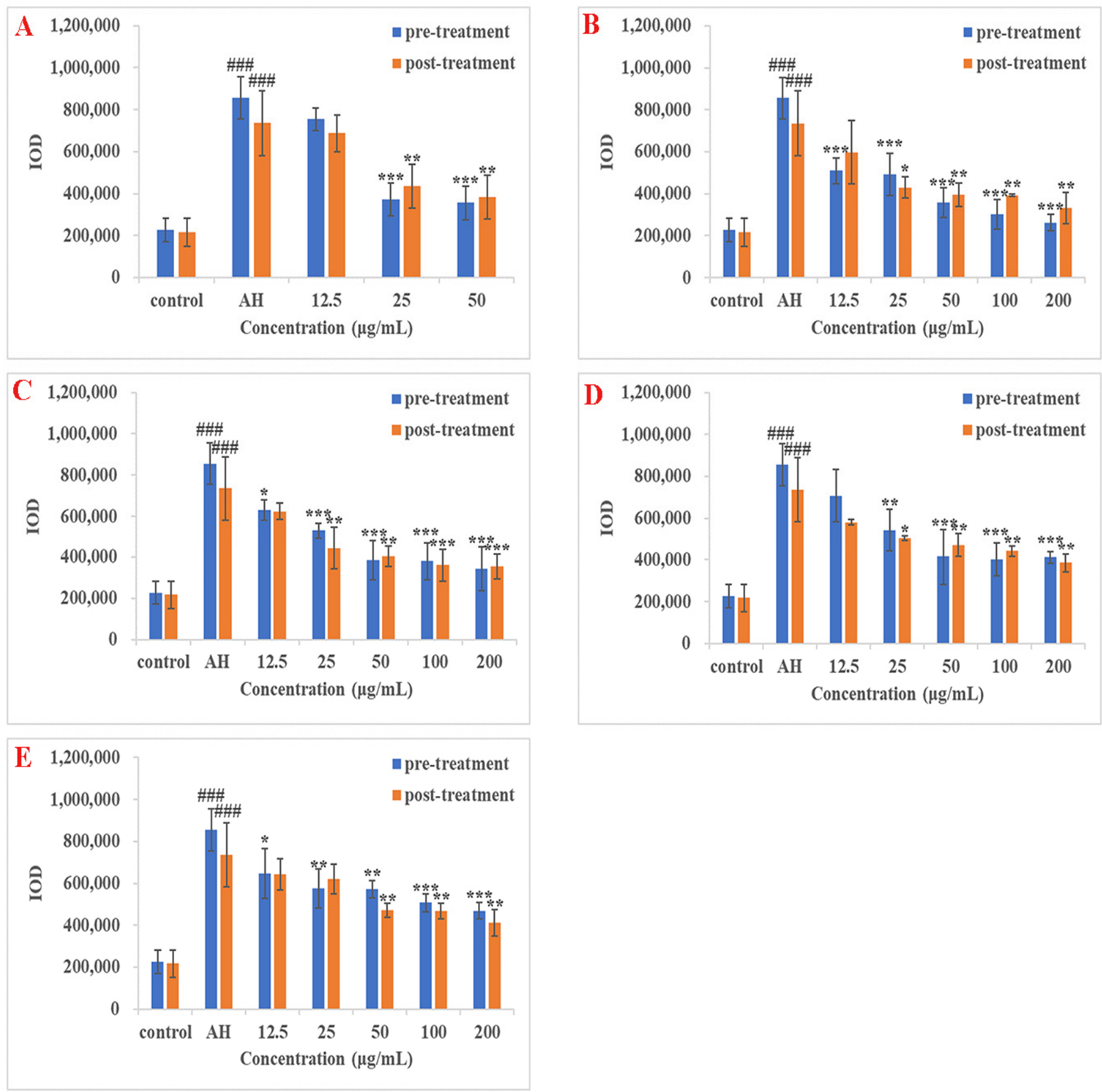

Figure 4. Result of the anti-thrombotic effect of DS components in AH-induced zebrafish thrombosis model. (A-E) indicated the results of ASP, SAB, MA, LA, and LG, respectively. The blue bar indicated the IOD value of the pre-treatment group, while the orange bar indicated the IOD value of the post-treatment group. ${ }^{\# \# \# ~} p<0.001$ versus control group; ${ }^{*} p<0.05$, ** $p<0.01$ and ${ }^{* * *} p<0.001$ versus AH group. 
Table 5. Anti-thrombotic effects of DS compounds on AH-induced zebrafish thrombosis.

\begin{tabular}{|c|c|c|c|c|c|}
\hline DS Compounds & $\begin{array}{c}\text { Concentrations } \\
(\mu \mathrm{g} / \mathrm{mL})\end{array}$ & $\begin{array}{l}\text { Pre-Treatment } \\
\text { Efficacy }(\%)\end{array}$ & $\begin{array}{l}\text { Pre-Treatment } \\
\mathrm{IC}_{50}(\mu \mathrm{g} / \mathrm{mL})\end{array}$ & $\begin{array}{l}\text { Post-Treatment } \\
\text { Efficacy }(\%)\end{array}$ & $\begin{array}{l}\text { Post-Treatment } \\
\mathrm{IC}_{50}(\mu \mathrm{g} / \mathrm{mL})\end{array}$ \\
\hline \multirow{3}{*}{ ASP } & 12.5 & 16.06 & \multirow{3}{*}{19.08} & 9.23 & \multirow{3}{*}{27.22} \\
\hline & 25 & 77.01 & & 57.59 & \\
\hline & 50 & 79.39 & & 68.04 & \\
\hline \multirow{5}{*}{ SAB } & 12.5 & 54.90 & \multirow{5}{*}{12.22} & 26.68 & \multirow{5}{*}{27.23} \\
\hline & 25 & 57.71 & & 58.95 & \\
\hline & 50 & 79.05 & & 65.63 & \\
\hline & 100 & 87.98 & & 66.08 & \\
\hline & 200 & 94.21 & & 77.88 & \\
\hline \multirow{5}{*}{ MA } & 12.5 & 35.69 & \multirow{5}{*}{22.07} & 21.43 & \multirow{5}{*}{31.03} \\
\hline & 25 & 51.65 & & 55.87 & \\
\hline & 50 & 74.63 & & 63.73 & \\
\hline & 100 & 75.34 & & 72.39 & \\
\hline & 200 & 81.38 & & 73.49 & \\
\hline \multirow{5}{*}{ LA } & 12.5 & 23.52 & \multirow{5}{*}{31.12} & 29.87 & \multirow{5}{*}{50.62} \\
\hline & 25 & 49.61 & & 44.55 & \\
\hline & 50 & 69.93 & & 50.66 & \\
\hline & 100 & 71.97 & & 56.48 & \\
\hline & 200 & 70.64 & & 67.45 & \\
\hline \multirow{5}{*}{ LG } & 12.5 & 33.17 & \multirow{5}{*}{62.75} & 17.58 & \multirow{5}{*}{85.22} \\
\hline & 25 & 44.34 & & 21.97 & \\
\hline & 50 & 45.09 & & 51.07 & \\
\hline & 100 & 55.21 & & 51.29 & \\
\hline & 200 & 61.34 & & 62.57 & \\
\hline
\end{tabular}

In the PHZ-induced thrombus treatment groups, statistically significant anti-thrombotic effects in pre-treatment zebrafish groups were observed at 25 and $50 \mu \mathrm{g} / \mathrm{mL}(p<0.05)$ for ASP; $12.5 \mu \mathrm{g} / \mathrm{mL}(p<0.01), 25,50,100$, and $200 \mu \mathrm{g} / \mathrm{mL}(p<0.001)$ for SAB; $12.5 \mu \mathrm{g} / \mathrm{mL}$ $(p<0.01), 25,50,100$, and $200 \mu \mathrm{g} / \mathrm{mL}(p<0.001)$ for MA; 12.5 and $25 \mu \mathrm{g} / \mathrm{mL}(p<0.05)$, $50 \mu \mathrm{g} / \mathrm{mL}(p<0.01), 100$ and $200 \mu \mathrm{g} / \mathrm{mL}(p<0.001)$ for LA; 50, 100 and $200 \mu \mathrm{g} / \mathrm{mL}$ $(p<0.01)$ for LG. These results are shown in Figure 5 . The $\mathrm{IC}_{50}$ of ASP, SAB, MA, LA, and LG were calculated as $37.28,11.28,15.47,50.59$, and $55.34 \mu \mathrm{g} / \mathrm{mL}$, respectively (Table 6). Statistically significant anti-thrombotic effects in post-treatment zebrafish groups were observed at $12.5 \mu \mathrm{g} / \mathrm{mL}(p<0.05), 25$ and $50 \mu \mathrm{g} / \mathrm{mL}(p<0.001)$ for ASP; 12.5, 25, 50, 100, and $200 \mu \mathrm{g} / \mathrm{mL}(p<0.001)$ for SAB; 12.5, 25, 50, 100, and $200 \mu \mathrm{g} / \mathrm{mL}(p<0.001)$ for MA; $12.5 \mu \mathrm{g} / \mathrm{mL}(p<0.05), 25 \mu \mathrm{g} / \mathrm{mL}(p<0.01), 50,100$, and $200 \mu \mathrm{g} / \mathrm{mL}(p<0.001)$ for LA; 12.5 and $25 \mu \mathrm{g} / \mathrm{mL}(p<0.01), 50,100$, and $200 \mu \mathrm{g} / \mathrm{mL}(p<0.001)$ for LG (Figure 5). The $\mathrm{IC}_{50}$ of ASP, SAB, MA, LA, and LG were 15.56, 8.11, 10.72, 27.95, and $14.01 \mu \mathrm{g} / \mathrm{mL}$ respectively (Table 6). 

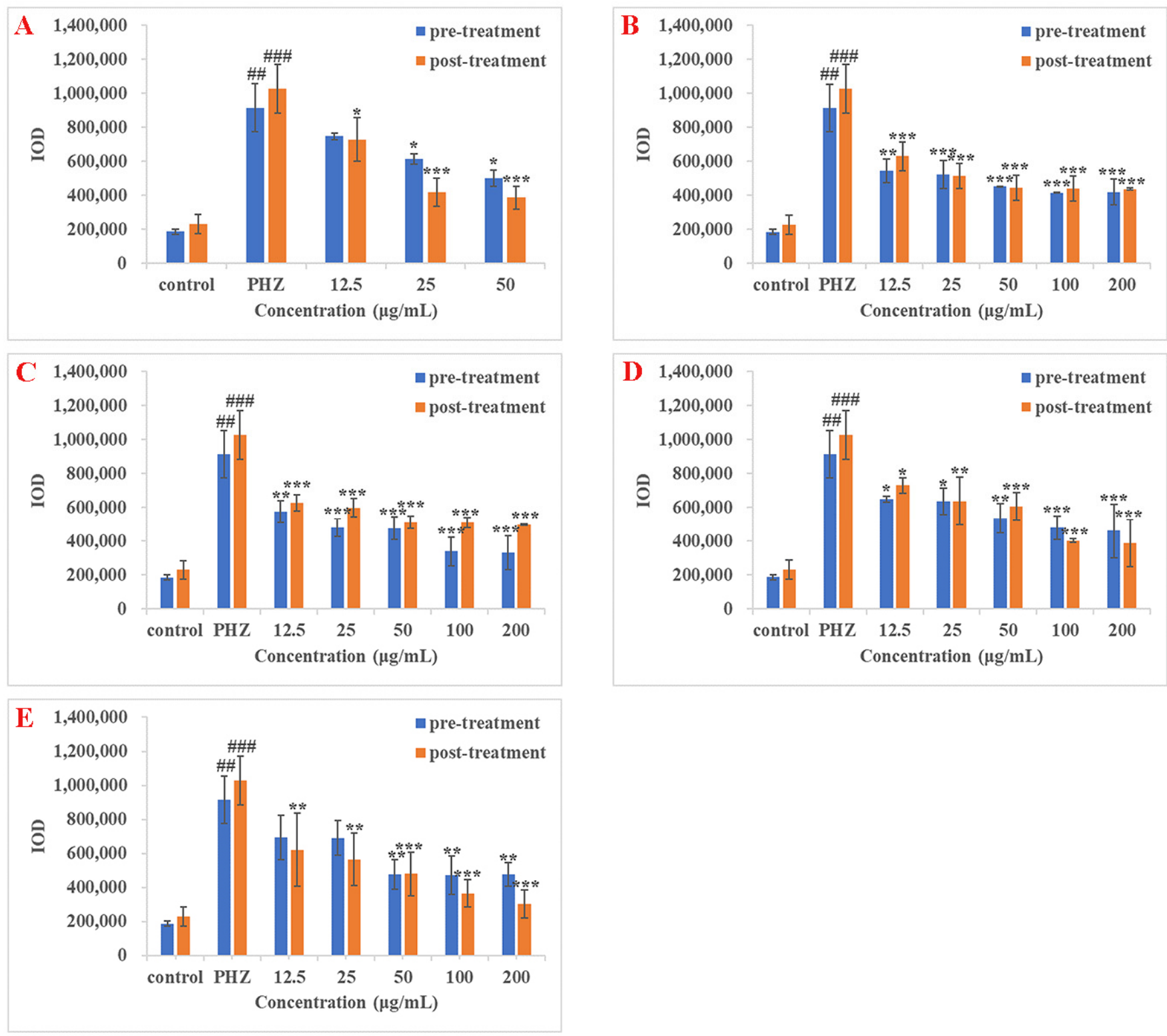

Figure 5. Result of the anti-thrombotic effect of DS components in PHZ-induced zebrafish thrombosis model. (A-E) indicated the results of ASP, SAB, MA, LA, and LG, respectively. The blue bar indicated the IOD value of the pre-treatment group, while the orange bar indicated the IOD value of the post-treatment group. ${ }^{\# \#} p<0.01,{ }^{\# \#} p<0.001$ versus control group; ${ }^{*} p<0.05,{ }^{* *} p<0.01$ and ${ }^{* * *} p<0.001$ versus PHZ group.

Table 6. Anti-thrombotic effects of DS compounds on PHZ-induced zebrafish thrombosis.

\begin{tabular}{|c|c|c|c|c|c|}
\hline DS Compounds & $\begin{array}{c}\text { Concentrations } \\
(\mu \mathrm{g} / \mathrm{mL})\end{array}$ & $\begin{array}{l}\text { Pre-Treatment } \\
\text { Efficacy (\%) }\end{array}$ & $\begin{array}{l}\text { Pre-Treatment } \\
\text { IC }_{50}(\mu \mathrm{g} / \mathrm{mL})\end{array}$ & $\begin{array}{c}\text { Post-Treatment } \\
\text { Efficacy (\%) }\end{array}$ & $\begin{array}{l}\text { Post-Treatment } \\
\mathrm{IC}_{50}(\mu \mathrm{g} / \mathrm{mL})\end{array}$ \\
\hline \multirow{3}{*}{ ASP } & 12.5 & 23.08 & \multirow{3}{*}{37.28} & 37.66 & \multirow{3}{*}{15.56} \\
\hline & 25 & 41.12 & & 76.29 & \\
\hline & 50 & 56.94 & & 80.27 & \\
\hline \multirow{5}{*}{$\mathrm{SAB}$} & 12.5 & 50.79 & \multirow{5}{*}{11.28} & 49.69 & \multirow{5}{*}{8.11} \\
\hline & 25 & 53.66 & & 64.43 & \\
\hline & 50 & 63.53 & & 73.10 & \\
\hline & 100 & 68.42 & & 73.40 & \\
\hline & 200 & 67.79 & & 74.00 & \\
\hline
\end{tabular}


Table 6. Cont.

\begin{tabular}{|c|c|c|c|c|c|}
\hline DS Compounds & $\begin{array}{c}\text { Concentrations } \\
(\mu \mathrm{g} / \mathrm{mL})\end{array}$ & $\begin{array}{l}\text { Pre-Treatment } \\
\text { Efficacy }(\%)\end{array}$ & $\begin{array}{l}\text { Pre-Treatment } \\
\text { IC }_{50}(\mu \mathrm{g} / \mathrm{mL})\end{array}$ & $\begin{array}{l}\text { Post-Treatment } \\
\text { Efficacy }(\%)\end{array}$ & $\begin{array}{l}\text { Post-Treatment } \\
\text { IC }_{50}(\mu \mathrm{g} / \mathrm{mL})\end{array}$ \\
\hline \multirow{5}{*}{ MA } & 12.5 & 46.48 & \multirow{5}{*}{15.47} & 50.15 & \multirow{5}{*}{10.72} \\
\hline & 25 & 59.87 & & 53.82 & \\
\hline & 50 & 60.10 & & 64.78 & \\
\hline & 100 & 79.05 & & 65.12 & \\
\hline & 200 & 79.84 & & 66.44 & \\
\hline \multirow{5}{*}{ LA } & 12.5 & 36.54 & \multirow{5}{*}{50.59} & 37.37 & \multirow{5}{*}{27.95} \\
\hline & 25 & 38.52 & & 48.93 & \\
\hline & 50 & 52.11 & & 52.90 & \\
\hline & 100 & 59.69 & & 78.32 & \\
\hline & 200 & 62.43 & & 80.13 & \\
\hline \multirow{5}{*}{ LG } & 12.5 & 30.33 & \multirow{5}{*}{55.34} & 50.89 & \multirow{5}{*}{14.01} \\
\hline & 25 & 30.77 & & 58.06 & \\
\hline & 50 & 60.26 & & 68.82 & \\
\hline & 100 & 60.85 & & 83.09 & \\
\hline & 200 & 60.21 & & 91.10 & \\
\hline
\end{tabular}

In conclusion, all of the four DS components, SAB, MA, LA, and LG exhibited a dose-dependent anti-thrombotic effect in AH/PHZ-induced zebrafish thrombosis model by both pre-treatment and post-treatment methods. Similar results were also observed in the ASP treatment group, which served as a positive control.

In recent years, polyphenols contained in fruits and vegetables had attracted considerable attention because of their benefits in human health, including the reduction of the risk of cardiovascular disease. SAB, MA, LA, and LG were all polyphenolic constitutions of DS and were proved to exert an anti-thrombotic effect in our study. Therefore, the result may suggest to a certain degree that the application of DS in TCM is coherent with the use of polyphenols in Western medicine for the treatment of cardiovascular disease.

\section{Materials and Methods}

\subsection{Chemicals and Reagents}

N-Phenylthiourea (PTU), phenylhydrazine (PHZ), ( \pm )-epinephrine hydrochloride (AH), acetylsalicylic acid (aspirin, ASP), ethyl 3-aminobenzoate methanesulfonate (MS-222) and 3,3'-dimethoxybenzidine (O-dianisidine) were purchased from Shanghai Aladdin Biochemical Technology Co., Ltd. (Shanghai, China). Salvianolic acid B (SAB), rosmarinic acid (MA) and dimethyl sulfoxide (DMSO) were purchased from Shanghai Macklin Biochemical Co., Ltd. (Shanghai, China). Lithospermic acid (LA) was purchased from Chengdu Must Bio-Technology Co., Ltd. (Chengdu, China). Luteolin-7-O- $\beta$-D-glucoside (LG) was purchased from Shanghai Standard Technology Co., Ltd. (Shanghai, China). Gelatin was purchased from Beyotime Biotech Inc. Hydrogen peroxide $\left(30 \%, \mathrm{H}_{2} \mathrm{O}_{2}\right)($ AR) was purchased from Chengdu Kelong Chemical Co., Ltd. (Chengdu, China). Sodium acetate anhydrous $\left(\mathrm{CH}_{3} \mathrm{COONa}\right)(\mathrm{AR})$ was purchased from Tianjin Zhiyuan Chemical Reagent $\mathrm{Co}$., Ltd. (Tianjin, China). Ethanol (AR) was purchased from Chongqing Chuandong Chemical (Group) Co., Ltd. (Chongqing, China). Other regular reagents for the daily maintenance of zebrafish system were purchased from Wuhan TianZhengYuan Biological Technology Co., Ltd. (Wuhan, China). DS compounds stock solutions were prepared in experimental water, DMSO, or absolute ethanol.

\subsection{Maintenance and Husbandry of Zebrafish}

Wild-type AB strain adult zebrafish were purchased from the Shanghai FishBio Co., Ltd. (Shanghai, China). Zebrafish were raised and kept in a flow-through farming system provided by Nanjing Eze Rinka Biotechnology Co., Ltd. (Nanjing, China) according to the standard procedure of China Zebrafish Resource Center. Zebrafish were maintained in 
light (under a 14:10 h light/dark cycle) and temperature $\left(25-28^{\circ} \mathrm{C}\right)$-controlled conditions in water ( $\mathrm{pH} 7.2-7.8$ and conductivity 450-550 $\mu \mathrm{s} / \mathrm{cm}$ ) and fed twice daily with live brine shrimp and dry flake food. Embryos were obtained from spawning adults in a breeding chamber overnight with a sex ratio of 2:1 (male/female) according to the standard zebrafish breeding protocol.

\subsection{Molecular Docking Studies}

The structures of molecules of active ingredients in DS were obtained from TCMSP and saved to files in mol2 format. With Gasteiger-Huckel charge, Tripos force field, and the Powell energy gradient method, all molecules were optimized in SYBYL 2.0 software (TRIPOS, Inc., St. Louis, MO, USA). The Powell energy gradient method was used to optimize the molecules by setting the maximum number of times to 10,000 and the energy convergence level difference to $0.005 \mathrm{Kcal} / \mathrm{mol}[22,32]$ and the rest of the parameters were set to default values. According to this method, the lowest energy small molecule structure is regarded as the active conformation.

Target proteins related to thrombus were searched from the TTD and UniProt database. The crystal structure of the protein came from the PDB database. Prior to docking studies, proteins needed to be pre-treated, including residual repairs, energy minimization, the addition of hydrogen atoms, as well as the removal of co-crystallized ligands, water molecules, and metal ions from the complexes.

Molecular docking was carried out using a standard Surflex-Dock protocol in SYBYL 2.0 software. The docking pocket was formed with amino acid residues at $0.5 \AA$ in the range of the original ligand molecule, and the remaining parameters were set as default. The original ligand was redocked into the binding pocket to verify the reliability of the docking method [22,32]. Then, compounds were docked into the binding pocket using the same parameters. Afterwards, by comparing the docking score with the original ligand, compounds with a higher value were screened out.

\subsection{Preparation of Solutions and Samples}

First, $2.64 \mathrm{mg}$ of $\mathrm{AH}$ was dissolved in $50 \mu \mathrm{L}$ DMSO to prepare $240 \mathrm{mM}$ stock solution, and $2.36 \mu \mathrm{L}$ PHZ was dissolved in $997.64 \mu \mathrm{L}$ absolute ethanol to prepare $24 \mathrm{mM}$ stock solution. These stock solutions were further diluted to working solutions with $0.2 \mathrm{mM}$ PTU-containing water, and the final concentrations of DMSO and absolute ethanol were kept below $0.1 \%$. Thirty milligrams $\mathrm{O}$-dianisidine and $41 \mathrm{mg} \mathrm{CH}_{3} \mathrm{COONa}$ were dissolved in $20 \mathrm{~mL}$ of absolute ethanol as the stock solution; and then, $128 \mu \mathrm{L} \mathrm{30 \%} \mathrm{H}_{2} \mathrm{O}_{2}$ and $20 \mathrm{~mL}$ of water were added to form O-dianisidine working solution. ASP, SAB, MA, LA, and LG were dissolved in DMSO to form the stock solutions; then, they were further diluted to working solutions $(12.5,25,50,100$, and $200 \mu \mathrm{g} / \mathrm{mL})$ with $0.2 \mathrm{mM}$ PTU-containing water.

\subsection{AH/PHZ-Induced Zebrafish Thrombosis Model and DS Compounds Treatment}

The zebrafish were raised in the water containing $0.2 \mathrm{mM}$ PTU from $24 \mathrm{hpf}$ (hours post fertilization) during all of the experiments. Two thrombus chemical inducers, $\mathrm{AH}$ or PHZ, were used respectively in zebrafish to induce the thrombosis model. Zebrafish embryos were applied to treatment in 24-well plates containing 15 fish per well; three parallel wells were set per treatment group. In the control group, zebrafish were treated with $0.1 \%$ DMSO or $0.1 \%$ absolute ethanol, respectively. In the $\mathrm{AH} / \mathrm{PHZ}$ treatment group (AH/PHZ group), $15 \mu \mathrm{M}$ AH or $1.5 \mu \mathrm{M}$ PHZ were treated to $78 \mathrm{hpf}$ zebrafish for $16 \mathrm{~h}$ or $24 \mathrm{~h}$, respectively. In the ASP treatment group (ASP group), as a positive control, ASP (12.5, $25,50,100$, and $200 \mu \mathrm{g} / \mathrm{mL}$ ) was treated to zebrafish for $24 \mathrm{~h}$ either before (pre-treatment) or after (post-treatment) $\mathrm{AH} / \mathrm{PHZ}$ treatment. In the DS compounds treatment group, SAB $(12.5,25,50,100,200 \mu \mathrm{g} / \mathrm{mL}), \mathrm{MA}(12.5,25,50,100,200 \mu \mathrm{g} / \mathrm{mL}), \mathrm{LA}(12.5,25,50,100$, $200 \mu \mathrm{g} / \mathrm{mL})$, and LG $(12.5,25,50,100,200 \mu \mathrm{g} / \mathrm{mL})$ were treated to zebrafish for $24 \mathrm{~h}$ either before (pre-treatment) or after (post-treatment) AH/PHZ treatment, respectively. 
After DS compounds treatment, zebrafish were stained in the dark with O-dianisidine staining solution for $30 \mathrm{~min}$. Then, the O-dianisidine working solution was abandoned, and the zebrafish were washed by DMSO three times. All of the images were taken at the same magnification, with an upright fluorescence microscopy imaging system. The software used to capture the images was cellSens Standard.

Zebrafish from each group were picked out for image capture of the heart and caudal vein RBCs, respectively. The images were quantitatively analyzed using Image-Pro Plus 6.0 according to IOD value. The anti-thrombotic effects of the test compounds were evaluated based on the formula below:

$$
\begin{gathered}
\text { Efficacy }(\%)=\left[\left[\operatorname{IOD}_{(\text {treatment group })}-\mathrm{IOD}_{(\mathrm{AH} / \mathrm{PHZ} \text { group })}\right] /\left[\mathrm{IOD}_{(\text {control group })}-\mathrm{IOD}_{(\mathrm{AH} / \mathrm{PHZ} \text { group })}\right]\right] \times 100 \% \\
\mathrm{IC}_{50} \text { was calculated with GraphPad Prism } 8 .
\end{gathered}
$$

\subsection{Ethics Statements}

All zebrafish experiments were conducted according to the guidelines of the Animal Ethics Committee of the School of Pharmacy and Bioengineering, Chongqing University of Technology.

\subsection{Statistical Analysis}

All data were expressed as the mean \pm the standard error of mean (SEM) of three different experiments. Multiple group comparison was conducted by one-way analysis of variance (ANOVA) of IBM SPSS Statistics 19. A $p$-value of less than 0.05 was considered as statistically significant.

\section{Conclusions}

In this study, a rapid and effective method for anti-thrombotic effects screening in DS was established based on the zebrafish in vivo assay and computational studies of molecular docking. Molecular docking studies showed that SAB, MA, LA, and LG from DS exhibited the good binding affinity to the thrombosis-related proteins. Furthermore, SAB, MA, LA, and LG exhibited anti-thrombotic effects in the chemical-induced zebrafish thrombosis model. This study demonstrated a feasible approach for the screening of pharmacological effect of small molecules by combining a zebrafish in vivo model with molecular docking techniques. Meanwhile, our research also provided references for the further study of therapeutic effects of DS to thrombosis-related diseases.

Author Contributions: H.T.: Investigation, writing —original draft. N.Q.: Conceptualization, investigation, writing —review and editing. C.R.: visualization. J.Z.: methodology. H.W.: data curation. G.H.: writing - review and editing, supervision, project administration, funding acquisition. All authors have read and agreed to the published version of the manuscript.

Funding: This research was funded by the "National Natural Science Foundation of China (81703687)" and "Science and Technology Research Program of Chongqing Municipal Education Commission (Grant No. KJQN201801131)".

Institutional Review Board Statement: All animal studies were conducted in strict accordance with the recommendations in the Guide for the Care and Use of Laboratory Animals of the Ministry of Science and Technology of the People's Republic of China. The protocols for zebrafish studies were approved by the Committee on the Ethics of Animal Experiments of Chongqing University of Technology (approval number: 202115).

Informed Consent Statement: Not applicable.

Data Availability Statement: The data presented in this study are contained within the article.

Conflicts of Interest: All the authors declare that they have no conflict of interest.

Sample Availability: Samples of all of the compounds are available from the authors. 


\section{References}

1. Engelmann, B.; Massberg, S. Thrombosis as an intravascular effector of innate immunity. Nat. Rev. Immunol. 2013, 13, 34-45. [CrossRef] [PubMed]

2. Chen, Y.; Chen, P.D.; Bao, B.H.; Shan, M.Q.; Zhang, K.C.; Cheng, F.F.; Cao, Y.D.; Zhang, L.; Ding, A.W. Anti-thrombotic and pro-angiogenic effects of Rubia cordifolia extract in zebrafish. J. Ethnopharmacol. 2018, 219, 152-160. [CrossRef] [PubMed]

3. Aksu, K.; Donmez, A.; Keser, G. Inflammation-induced thrombosis: Mechanisms, disease associations and management. Curr. Pharm. Des. 2012, 18, 1478-1493.

4. Zitomersky, N.L.; Verhave, M.; Trenor, C.C., 3rd. Thrombosis and inflammatory bowel disease: A call for improved awareness and prevention. Inflamm. Bowel Dis. 2011, 17, 458-470. [CrossRef] [PubMed]

5. Vermeersch, E.; Denorme, F.; Maes, W.; De Meyer, S.F.; Vanhoorelbeke, K.; Edwards, J.; Shevach, E.M.; Unutmaz, D.; Fujii, H.; Deckmyn, H.; et al. The role of platelet and endothelial GARP in thrombosis and hemostasis. PLoS ONE 2017, 12, e0173329. [CrossRef]

6. Stowell, S.R.; Stowell, C.P. Biologic roles of the ABH and Lewis histo-blood group antigens part II: Thrombosis, cardiovascular disease and metabolism. Vox Sang. 2019, 114, 535-552. [CrossRef]

7. Qi, Y.; Zhao, X.; Liu, H.; Wang, Y.; Zhao, C.; Zhao, T.; Zhao, B.; Wang, Y. Identification of a Quality Marker (Q-Marker) of Danhong Injection by the Zebrafish Thrombosis Model. Molecules 2017, 22, 1443. [CrossRef]

8. Shu, Y.; Liu, Z.; Zhao, S.; Song, Z.; He, D.; Wang, M.; Zeng, H.; Lu, C.; Lu, A.; Liu, Y. Integrated and global pseudotargeted metabolomics strategy applied to screening for quality control markers of Citrus TCMs. Anal. Bioanal. Chem. 2017, 409, 4849-4865. [CrossRef]

9. Yang, B.; Wang, Y.; Shan, L.; Zou, J.; Wu, Y.; Yang, F.; Zhang, Y.; Li, Y.; Zhang, Y. A Novel and Practical Chromatographic "Fingerprint-ROC-SVM" Strategy Applied to Quality Analysis of Traditional Chinese Medicine Injections: Using KuDieZi Injection as a Case Study. Molecules 2017, 22, 1237. [CrossRef]

10. Zhang, H.; Wang, W.R.; Lin, R.; Zhang, J.Y.; Ji, Q.L.; Lin, Q.Q.; Yang, L.N. Buyang Huanwu decoction ameliorates coronary heart disease with Qi deficiency and blood stasis syndrome by reducing CRP and CD40 in rats. J. Ethnopharmacol. 2010, 130, 98-102. [CrossRef]

11. Li, H.X.; Han, S.Y.; Wang, X.W.; Ma, X.; Zhang, K.; Wang, L.; Ma, Z.Z.; Tu, P.F. Effect of the carthamins yellow from Carthamus tinctorius L. on hemorheological disorders of blood stasis in rats. Food Chem. Toxicol. 2009, 47, 1797-1802. [CrossRef] [PubMed]

12. Yin, S.J.; Luo, Y.Q.; Zhao, C.P.; Chen, H.; Zhong, Z.F.; Wang, S.; Wang, Y.T.; Yang, F.Q. Antithrombotic effect and action mechanism of Salvia miltiorrhiza and Panax notoginseng herbal pair on the zebrafish. Chin. Med. 2020, 15, 35. [CrossRef] [PubMed]

13. Yuan, T.; Chen, Y.; Zhou, X.; Lin, X.; Zhang, Q. Effectiveness and safety of Danshen injection on heart failure: Protocol for a systematic review and meta-analysis. Medicine (Baltimore) 2019, 98, e15636. [CrossRef]

14. Zhou, L.; Zuo, Z.; Chow, M.S. Danshen: An overview of its chemistry, pharmacology, pharmacokinetics, and clinical use. J. Clin. Pharmacol. 2005, 45, 1345-1359. [CrossRef] [PubMed]

15. Mao, H.P.; Wang, X.Y.; Gao, Y.H.; Chang, Y.X.; Chen, L.; Niu, Z.C.; Ai, J.Q.; Gao, X.M. Danhong injection attenuates isoproterenolinduced cardiac hypertrophy by regulating p38 and NF-kb pathway. J. Ethnopharmacol. 2016, 186, 20-29. [CrossRef] [PubMed]

16. Zhu, X.Y.; Liu, H.C.; Guo, S.Y.; Xia, B.; Song, R.S.; Lao, Q.C.; Xuan, Y.X.; Li, C.Q. A Zebrafish Thrombosis Model for Assessing Antithrombotic Drugs. Zebrafish 2016, 13, 335-344. [CrossRef]

17. Wang, J.; Xiong, X.; Feng, B. Cardiovascular effects of salvianolic Acid B. Evid. Based Complement. Altern. Med. 2013, 2013, 247948. [CrossRef]

18. Wang, X.; Zhang, Y.L.; Xiang, Y.H.; Ren, Z.Z.; Qiao, Y.J. Identification of thrombin inhibitors from Salvia Miltiorrhiza by pharmacophore based virtual screening and molecular docking. Chin. J. Tradit. Chin. Med. Pharm. 2013, 28, 6.

19. Sheng, S.; Wang, J.; Wang, L.; Liu, H.; Li, P.; Liu, M.; Long, C.; Xie, C.; Xie, X.; Su, W. Network pharmacology analyses of the antithrombotic pharmacological mechanism of Fufang Xueshuantong Capsule with experimental support using disseminated intravascular coagulation rats. J. Ethnopharmacol. 2014, 154, 735-744. [CrossRef]

20. Chu, H.; He, Q.X.; Wang, J.W.; Deng, Y.T.; Wang, J.; Hu, Y.; Wang, Y.Q.; Lin, Z.H. 3D-QSAR, molecular docking, and molecular dynamics simulation of a novel thieno [3, 4-d]pyrimidine inhibitor targeting human immunodeficiency virus type 1 reverse transcriptase. J. Biomol. Struct. Dyn. 2020, 38, 4567-4578. [CrossRef]

21. Fang, Y.; Lu, Y.; Zang, X.; Wu, T.; Qi, X.; Pan, S.; Xu, X. 3D-QSAR and docking studies of flavonoids as potent Escherichia coli inhibitors. Sci. Rep. 2016, 6, 23634. [CrossRef] [PubMed]

22. He, Q.; Chu, H.; Wang, Y.; Guo, H.; Wang, Y.; Wang, S.; Feng, Z.; Xie, X.Q.; Hu, Y.; Liu, H.; et al. In silico design novel vibsanin B derivatives as inhibitor for heat shock protein 90 based on 3D-QSAR, molecular docking and molecular dynamics simulation. J. Biomol. Struct. Dyn. 2020, 38, 4313-4324. [CrossRef]

23. Weyand, A.C.; Shavit, J.A. Zebrafish as a model system for the study of hemostasis and thrombosis. Curr. Opin. Hematol. 2014, 21, 418-422. [CrossRef]

24. Gregory, M.; Hanumanthaiah, R.; Jagadeeswaran, P. Genetic analysis of hemostasis and thrombosis using vascular occlusion. Blood Cells Mol. Dis. 2002, 29, 286-295. [CrossRef] [PubMed]

25. Lang, M.R.; Gihr, G.; Gawaz, M.P.; Müller, I.I. Hemostasis in Danio rerio: Is the zebrafish a useful model for platelet research? J. Thromb. Haemost. 2010, 8, 1159-1169. [CrossRef] 
26. Khandekar, G.; Kim, S.; Jagadeeswaran, P. Zebrafish thrombocytes: Functions and origins. Adv. Hematol. 2012, $2012,857058$. [CrossRef] [PubMed]

27. Jagadeeswaran, P. Zebrafish: A tool to study hemostasis and thrombosis. Curr. Opin. Hematol. 2005, 12, 149-152. [CrossRef]

28. Ma, D.; Zhang, J.; Lin, H.F.; Italiano, J.; Handin, R.I. The identification and characterization of zebrafish hematopoietic stem cells. Blood. 2011, 118, 289-297. [CrossRef]

29. Lieschke, G.J.; Currie, P.D. Animal models of human disease: Zebrafish swim into view. Nat. Rev. Genet. 2007, 8, 353-367. [CrossRef]

30. Lu, S.; Hu, M.; Wang, Z.; Liu, H.; Kou, Y.; Lyu, Z.; Tian, J. Generation and Application of the Zebrafish heg1 Mutant as a Cardiovascular Disease Model. Biomolecules 2020, 10, 1542. [CrossRef]

31. Li, J.; Liu, H.; Yang, Z.; Yu, Q.; Zhao, L.; Wang, Y. Synergistic Effects of Cryptotanshinone and Senkyunolide I in Guanxinning Tablet Against Endogenous Thrombus Formation in Zebrafish. Front. Pharmacol. 2021, 11, 622787. [CrossRef] [PubMed]

32. He, Q.; Han, C.; Li, G.; Guo, H.; Wang, Y.; Hu, Y.; Lin, Z.; Wang, Y. In silico design novel (5-imidazol-2-yl-4-phenylpyrimidin2-yl)[2-(2-pyridylamino)ethyl]amine derivatives as inhibitors for glycogen synthase kinase 3 based on 3D-QSAR, molecular docking and molecular dynamics simulation. Comput. Biol. Chem. 2020, 88, 107328. [CrossRef] [PubMed] 